\title{
Lack of neo-sensitization to Pen a 1 in patients treated with mite sublingual immunotherapy
}

\author{
Renato E Rossi*1, Giorgio Monasterolo2, Cristoforo Incorvaia33, Philippe Moingeon4, Franco Frati5, \\ Giovanni Passalacqua6, Lucilla Rossi and Giorgio W Canonica6
}

\begin{abstract}
Background: Some studies reported the possible induction of food allergy, caused by neo-sensitization to crossreacting allergens, during immunotherapy with aeroallergens, while other studies ruled out such possibility.

Objectives: The aim of this study was to evaluate the development of neo-sensitization to Pen a 1 (tropomyosin) as well as the appearance of reactions after ingestion of foods containing tropomyosin as a consequence of sublingual mite immunization.

Materials and methods: Specific lgE to Tropomyosin (rPen a 1) before and after mite sublingual immunotherapy in 134 subjects were measured. IgE-specific antibodies for mite extract and recombinant allergen Pen a 1 were evaluated using the immunoenzymatic CAP system (Phadia Diagnostics, Milan, Italy).

Results: All patients had rPen a $1 \mathrm{IgE}$ negative results before and after mite SLIT and did not show positive shrimp extract skin reactivity and serological rPen a $1 \mathrm{lgE}$ conversion after treatment. More important, no patient showed systemic reactions to crustacean ingestion.
\end{abstract}

Conclusions: Patients did not show neo-sensitization to tropomyosin, a component of the extract (namely mite group 10) administered. An assessment of a patient's possible pre-existing sensitisation to tropomyosin by skin test and/or specific lgE prior to start mite extract immunotherapy is recommended.

Trial Registration: This trial is registered in EudraCT, with the ID number of 2010-02035531.

\section{Introduction}

In developed countries respiratory allergy is an important cause of chronic illness [1] and has a significant socio-economic impact [2]. As stated in consensus documents, allergen specific immunotherapy (SIT) is the only curative approach to treat respiratory allergic diseases $[3,4]$. As a matter of fact, commercial extracts used for SIT contain all or almost all the sensitizing molecules, including major and minor allergens, whereas patients receiving the treatment may be sensitized to only some of them. This raises the question of whether the administration of allergen extracts during immunotherapy can induce new clinically relevant sensitizations [5], that is the appearance of IgE specific for other allergenic molecules. Some studies have, in fact, reported the development of new sensitizations to aller-

\footnotetext{
* Correspondence: immunoway@libero.it

1 Allergy Unit, National Health Service, Rete di Allergologia Regione Piemonte, Cuneo 1, Italy

Full list of author information is available at the end of the article
}

genic components during subcutaneous immunotherapy (SCIT) with grass pollen [6] and birch pollen [7], but the clinical impact of such new sensitizations remained unexplored. On the other hand, there have been convincing reports about the onset of clinical manifestations of food allergy to snails or crustaceans in patients receiving SLIT with mite extracts $[8,9]$. This effect can be attributable to the emergence of specific IgE to tropomyosin, a group 10 component of the mite extracts, which is shared also by snails, shrimps and lobsters. In the case of shrimps, tropomyosin is the major allergen Pen a 1 [10-13]. Thus, it is important to assesss if de-novo sensitisation to tropomyosin occurs during mite immunotherapy, and if such sensitisation maybe of clinical relevance. The present study was designed to assess in real life the development of new sensitizations to Pen a 1 (tropomyosin), and the onset of reactions after ingestion of foods containing tropomyosin, as a possible consequence of sensitization to this allergen 
(Group 10, i.e. Der p 10) contained in the mite extracts for SIT $[11,13]$.

\section{Materials and methods Patients and immunotherapy}

Consecutive patients with ascertained respiratory allergy due to house dust mite, and prescribed with mite sublingual immunotherapy (SLIT) were evaluated at baseline (before starting the SLIT courses) and after three years of treatment, concerning their sensitisation to shrimp and positivity to Pen a 1 . The prescription of mite-SLIT was made according to guidelines, in the presence of a case history consistent with mite allergy, that is symptoms of persistent rhinoconjuntivitis and/or mild to moderate asthma for at least 2 years. In addition they had to have a positive skin prick test to house dust mite extract and/or a positive CAPRAST assay ( $>.35 \mathrm{kU} / \mathrm{L})$. Exclusion criteria were previous treatment with SLIT or severe or uncontrolled asthma. SLIT was given as a standardized mite extract $\left(\right.$ Staloral $^{\mathbb{}}$, Stallergenes, Antony, France) at the concentration of $60 \mu \mathrm{g} /$ $\mathrm{ml}$ Der p 1, $12 \mu \mathrm{g} / \mathrm{ml}$ Der p 2 and $150 \mu \mathrm{g} / \mathrm{ml}$ Der f 1 . The content of group 10 allergen (tropomyosin), was as high as $19 \mu \mathrm{g} / \mathrm{ml}$. Matched patients receiving SLIT for grass (Staloral $300^{\circledR}$ ) for a cumulative dose of 7,560 $\mu \mathrm{g}$ of Phl p 5 in three years, were the control group. In addition, patients with ascertained reactions to shrimp were studied for their skin and in vitro reactivity to shrimp and mite, as positive controls. The outpatients were enrolled during the period from January 2005 to December 2007. All subjects or their parents signed an informed consent.

\section{In vivo tests}

Skin prick tests were performed with commercial extracts of dust mites (Alk-Abellò, Lainate, Milan, Italy) containing $40 \mu \mathrm{g} / \mathrm{ml}$ of Der p 1 and Der f 1 and $20 \mu \mathrm{g} / \mathrm{ml}$ of Der p 2 and Der $\mathrm{f} 2$. No information was given by the manufacturer about mite group 10 (tropomyosin) content. In addition, the following allergen extracts from the same manufacturer were used: Parietaria judaica (20 $\mu \mathrm{g} / \mathrm{ml}$ Par j 1), Phleum pratense $(60 \mu \mathrm{g} / \mathrm{ml} \mathrm{Phl} \mathrm{p} \mathrm{5),} \mathrm{birch} \mathrm{(} 45 \mu \mathrm{g} / \mathrm{ml}$ Bet $\mathrm{v} 1)$, olive $(60 \mu \mathrm{g} / \mathrm{ml}$ of Ole e 1), mugwort (135 $\mu \mathrm{g} / \mathrm{ml} \mathrm{Art} \mathrm{v} \mathrm{1)} \mathrm{and} \mathrm{cat}$ dander $(60 \mu \mathrm{g} / \mathrm{ml} \mathrm{Fel} \mathrm{d} \mathrm{1).} \mathrm{All} \mathrm{patients} \mathrm{were} \mathrm{also} \mathrm{skin} \mathrm{tested}$ with a shrimp extract (Stallergenes) before and after SLIT.

\section{In vitro tests}

IgE-specific antibodies for mite extract and recombinant allergen Pen a 1 obtained from Penaeus aztecus was evaluated using the immunoenzymatic CAP system (Phadia Diagnostics, Milan, Italy) according to the manufacturer's instructions. The results were expressed in classes of positive results from 0 to 6 , where class 0 corresponds to up to $0.35 \mathrm{kUA} / \mathrm{l}$; class 1 to $0.35-0.7 \mathrm{kUA} / \mathrm{l}$; class 2 to $0.7-3.5$ $\mathrm{kUA} / \mathrm{l}$; class 3 to $3.5-17.5 \mathrm{kUA} / 1$; class 4 to $17.5-50 \mathrm{kUA} / \mathrm{l}$; class 5 to 50-100 and class 6 more than $100 \mathrm{kUA} / \mathrm{L}$.

\section{Results}

One hundred and thirty-four patients were enrolled for the study, received SLIT for their mite allergy and completed the 3-year course of treatment. The mean age of the patients was 29.4 years, and 64 of them were male. The control group included 155 subjects (mean age 27.1 years, 83 male) who received SLIT for grass allergy. The two populations were homogeneous, for demographic and clinical characteristics, as shown in table 1. At baseline, serum IgE specific to Pen a 1 were undetectable in all the 288 subjects, and the skin prick test with the commercial shrimp extract was negative. After 3 years of SLIT with the mite extract, there was no emergence of Pen a 1-specific IgE as measured by CAPRAST. Also, the skin test performed with the shrimp extracts remained negative in the two groups of subjects. There was no change in the pattern of skin sensitisation to mite and other allergens at the end of the SLIT course. Of the 134 patients receiving mite SLIT, all had certainly ate crustaceans (including shrimp) and seafood on more occasions during SLIT, and none of them reported adverse reactions. The same happened in the patients of the control group. In 6 patients with previous reactions after shrimp ingestion, the skin test with shrimp extract proved invariably positive, as well as the CAP assay to shrimp and the measurement of Pen a 1 specific IgE (Table 2). This showed that the shrimp extract efficiently detects the Pen a 1 positive subjects.

\section{Discussion}

The observations on development of new sensitizations induced by specific immunotherapy are contrasting. Studies demonstrating new IgE reactivities to allergenic components in pollen extracts administered with SLIT did not report association with clinical symptoms [6,7]. Concerning dust mite immunotherapy, the relevant allergen is tropomyosin, occurring in mites, crustacean and molluscs and in a number of other invertebrates [10-13]. A first study found that SCIT with dust mite extract induced an increase of IgE response to snail or shrimp and the occurrence of clinical symptoms following their ingestion [8]. However, only in two patients, who were negative at baseline to tropomyosin, a new sensitization actually took place. There are reports that subjects already clinically allergic to foods containing tropomyosin may worsen their food allergy symptoms following mite immunotherapy $[14,15]$, but this is a different issue. Indeed, in a study on two groups of children, respectively treated or not by mite immunotherapy for a mean duration of 19 months, the only new sensitization to snail was found among children not treated with immunotherapy [16]. Of course, the eating habit is an important factor: in the study by Meglio et al less than $20 \%$ of children had previously eaten snails [16], but in the study by Asero et al all the included patients ate crustaceans and molluscs of any kind with no clinical reaction [9]. It is also true that a sensi- 
Table 1: Demographic, clinical and serological characteristics of 182 patients treated with sublingual vaccines

\begin{tabular}{lll}
\hline & Mite SLIT & Grass SLIT \\
\hline Number of patients & 134 & 155 \\
\hline Age (years), mean \pm SD & $29.4 \pm 14.1$ & $27.1 \pm 13.8$ \\
\hline Male (\%) & $64(48)$ & $83(53)$ \\
\hline Female & $70(52)$ & $72(47)$ \\
\hline Rhinitis (\%) & $73(54)$ & $99(63)$ \\
\hline Rhinitis+Asthma (\%) & $61(46)$ & $56(37)$ \\
\hline Pen a 1-negative subjects & 134 & 155 \\
\hline Mean SLIT duration (months) & $24.7(\min 12-\max 36)$ \\
\hline
\end{tabular}

tisation to shrimp's tropomyosin can be found in subjects allergic to mites who never ate shrimps or shellfish [17].

We studied patients living in a geographic area in the province of Cuneo in northwest Italy, where molluscs are widely consumed as part of the local gastronomic tradition. There are two small cities specifically within the area, Borgo San Dalmazzo and Cherasco, where the consumption of snails in particular is quite high; snails are even the sub- ject of frequent local culinary festivals. All patients had a personal histories free from systemic allergic reactions to crustaceans and molluscs (oysters, snails, prawns, lobster etc.). The main finding of our study is that all 134 patients with negative rPen al IgE before starting immunotherapy, remained tropomyosin $\mathrm{IgE}$ negative after completing the mite immunotherapy course. Of course, an assessment of Der $p$ 10-specific IgE would have been more specific, but

Table 2: Characteristics of the shrimp-allergic patients

\begin{tabular}{|c|c|c|c|c|c|c|}
\hline Patient & 1 & 2 & 3 & 4 & 5 & 6 \\
\hline Age & 8 & 11 & 9 & 49 & 27 & 14 \\
\hline $\begin{array}{l}\text { Skin test to } \\
\text { mite (mm) }\end{array}$ & 8 & 7 & 11 & 6 & 8 & 5 \\
\hline $\begin{array}{l}\text { Skin test to } \\
\text { shrimp (mm) }\end{array}$ & 7 & 6 & 8 & 6 & 6 & 7 \\
\hline $\begin{array}{l}\text { slgE to mite } \\
(\mathrm{kUA} / \mathrm{l})\end{array}$ & 23.76 & $>100$ & 12.81 & 4.77 & 37.11 & 93.7 \\
\hline $\begin{array}{l}\text { slgE to shrimp } \\
(\mathrm{kUA} / \mathrm{l})\end{array}$ & 15.64 & $>100$ & 6.93 & 5.77 & 23.56 & 83.29 \\
\hline $\begin{array}{l}\text { slgE Pen a } 1 \\
(k \cup A / l)\end{array}$ & 18.15 & $>100$ & 9.73 & 64.23 & 21.89 & $>100$ \\
\hline
\end{tabular}


such reagent was not available at the time of the study. In addition, the shrimp skin test and shrimp-specific IgE assay proved positive in shrimp-allergic patients, so that the reliability of those tests in detecting positive subjects is reasonably ascertained.

To our knowledge the present paper is the first one in which the evaluation of a large number of patients treated with mite sublingual/oral vaccines did not result in a neosensitisation to tropomyosin, which was significantly present (as mite group 10) in the extract administered. This suggests that a persistent and continuative ingestion of a tropomyosin source as mite extract might not be enough to neo-sensitize mite allergic patients. The length of time a given subject receives SLIT seems also be a notable factor. The patients we studied had their treatment for a mean duration of more than 2 years, that may be considered a reasonable period in which a neo-sensitisation can occur. Although the occurrence of IgE reactivity to tropomyosin was reported in initial observations on patients treated with mite SCIT [8], a subsequent study specifically addressing the issue was unable to observe such phenomenon within a 3-year duration of mite SCIT [9]. Our findings demonstrate that also with prolonged SLIT neo-sensitisation to tropomyosin does not occur, and this was confirmed by negative skin tests to shrimp extract performed in all treated patients.

Obviously, the possibility of a neo-sensitisation to tropomyosin during SCIT or SLIT cannot be completely excluded. However, it is possible that occurrence of side effects induced by crustaceans or molluscs ingestion during mite immunotherapy could be due to lack of information about a pre-existent state of sensitisation to tropomyosin in these patients. To avoid possible allergic reactions to tropomyosin containing foods, we believe that assessment of a pre-existing sensitisation to tropomyosin by skin test and specific IgE measurement should be performed prior to start mite extract immunotherapy.

\section{Consent}

Written informed consent was obtained from the patient for publication of this article.

\section{Competing interests}

The authors declare that they have no competing interests.

\section{Authors' contributions}

RER conceived of the study, participated in its design, carried out the tests, analysed the results and participated to writing the manuscript

GM participated in the study design, carried out the tests, and analysed the results

$\mathrm{Cl}$ analysed the results and participated to writing the manuscript

PM analysed the results and participated to writing the manuscript

FF participated in the study design, analysed the results and participated to writing the manuscript

GP analysed the results and participated to writing the manuscript $L R$ carried out the tests and analysed the results

GWC analysed the results and participated to writing the manuscript

All authors read and approved the final manuscript.

\section{Author Details}

${ }^{1}$ Allergy Unit, National Health Service, Rete di Allergologia Regione Piemonte, Cuneo 1, Italy, ${ }^{2}$ Dipartimento di Analisi Chimico-Cliniche e Microbiologia, Ospedali di Fossano e Savigliano, Italy, ${ }^{3}$ Allergy/Pulmonary rehabilitation, ICP Hospital, Milan, Italy, ${ }^{4}$ Research and Development, Stallergènes SA, Antony, France, ${ }^{5}$ Medical and Scientific Department, Stallergenes, Milan, Italy, ${ }^{6}$ Allergy and Respiratory Diseases DIMI, University of Genoa Italy and 'Laboratorio

Centrale di Analisi, Istituto Gaslini, Genoa, Italy

Received: 4 November 2009 Accepted: 15 March 2010

Published: 15 March 2010

\section{References}

1. De Sario M, Galassi C, Biggeri A, Bisanti L, Ciccone G, Piffer S, et al.: Trends in the frequency of asthma and allergies. Epidemiol Prev 2005, 29(Suppl 2):86-90.

2. Nathan RA: The burden of allergic rhinitis. Allergy Asthma Proc 2007, 28:3-9.

3. Bousquet J, Lockey R, Malling HJ: Allergen immunotherapy: therapeutic vaccines for allergic diseases. A WHO position paper. JAllergy Clin Immunol 1998, 102:558-62.

4. Cox L, Li JT, Nelson H, Lockey R: Allergen immunotherapy: a practice parameter second update. J Allergy Clin Immunol 2007, 120:S25-85.

5. van Hage-Hamsten M, Valenta R: Specific immunotherapy - the induction of new lgE-specificities? Allergy 2002, 57:375-9.

6. Ball T, Sperr WR, Valent P, Lidholm J, Spitzauer S, Ebner C, Kraft D, Valenta $R$ : Induction of antibody responses to new $B$ cell epitopes indicates vaccination character of allergen immunotherapy. Eur JImmuno/ 1999, 29:2026-36

7. Moverare R, Elfman L, Vesterinen E, Metso T, Haathela T: Development of new lgE specificities to allergic components in birch pollen extract during specific immunotherapy studied with immunoblotting and Pharmacia CAPsystem. Allergy 2002, 57:423-430.

8. van Ree R, Antonicelli L, Akkerdaas JH, Garritani MS, Albeerse RC, Bonifaz F: Possible induction of food allergy during miteimmunotherapy. Allergy 1996, 51:108-113.

9. Asero R: Lack of de novo sensitization to tropomyosin in a group of mite-allergic patients treated by house dust mitespecificimmunotherapy. Int Arch Allergy Immunol 2005, 137:62-65.

10. Thomas WR, Smith W-A, Hales BJ, Mills KL, O'Brien RM: Characterization and immunology of house mite allergens. Int Arch Allergy Immunol 2002, 129:1-18.

11. Ayuso R, Reese G, Leong-Kee S, Plante M, Lehrer SB: Molecular basis of arthropod cross-reactivity: IgE-binding cross-reactive epitopes of shrimp, house dust mite and cockroach tropomyosins. Int Arch Allergy Immunol 2002, 129:38-48.

12. Reese G, Ayuso R, Lehrer SB: Tropomyosin: an invertebratepanallergen. Int Arch Allergy Immunol 1999, 119:247-58.

13. Arlian LG, Morgan MS, Vyszenski-Moher DL, Sharra D: Cross-reactivity between storage and dust mites and between mites and shrimp. Exp Appl Acarol 2009, 47:159-72.

14. Peroni DG, Piacentini GL, Bodini A, Boner AL: Snail anaphylaxis during house dust mite immunotherapy. Pediatr Allergy Immunol 2000, 11:260-1.

15. Pajno GB, La Grutta S, Barberio G, Canonica GW, Passalacqua G: Harmful effect of immunotherapy in children with combined snail and miteallergy. J Allergy Clin Immunol 2002, 109:627-9.

16. Meglio P, Plantamura M, Arabito E, Falagiani P, Torre A, Rossi P: Does SIT to Der p protect from snail sensitization? Allergy 2002, 57:868-9.

17. Fernandes J, Reshef A, Patton L, Ayuso R, Reese G, Lehrer SB: Immunoglobulin $\mathrm{E}$ antibody reactivity to the major shrimp allergen, tropomyosin, in unexposed Orthodox Jews. Clin Exp Allergy 2003, 33:956-61.

doi: $10.1186 / 1476-7961-8-4$

Cite this article as: Rossi et al., Lack of neo-sensitization to Pen a 1 in patients treated with mite sublingual immunotherapy Clinical and Molecular Allergy 2010, 8:4 